OPEN ACCESS

Edited by:

Bin Zhao,

Tsinghua University, China

Reviewed by:

Qianqian Zhang,

National Satellite Meteorological Center (NSMC), China

Hongrong Shi,

Institute of Atmospheric Physics

(CAS), China

Dan Chen,

China Meteorological Administration,

China

*Correspondence:

Rohini L. Bhawar

rohinibhawar@gmail.com

Specialty section:

This article was submitted to

Atmosphere and Climate,

a section of the journal

Frontiers in Environmental Science

Received: 23 July 2021

Accepted: 06 September 2021

Published: 20 September 2021

Citation:

Bhawar RL, Fadnavis S, Kumar V Rahul PRC, Sinha T and Lolli S (2021) Radiative Impacts of Aerosols During COVID-19 Lockdown Period Over the Indian Region.

Front. Environ. Sci. 9:746090. doi: 10.3389/fenvs.2021.746090

\section{Radiative Impacts of Aerosols During COVID-19 Lockdown Period Over the Indian Region}

\author{
Rohini L. Bhawar ${ }^{1 *}$, Suvarna Fadnavis ${ }^{2}$, Vinay Kumar ${ }^{3}$, P. R. C. Rahul ${ }^{2}$, Tushar Sinha ${ }^{3}$ and \\ Simone Lolli ${ }^{4}$ \\ ${ }^{1}$ Department of Atmospheric and Space Sciences, Savitribai Phule Pune University, Pune, India, ${ }^{2}$ Indian Institute of Tropical \\ Meteorology, Pune, India, ${ }^{3}$ Department of Environmental Engineering, Texas A\&M University, Kingsville, TX, United States, ${ }^{4} C N R$ - \\ IMAA, Potenza, Italy
}

The COVID-19 lockdown restrictions influenced global atmospheric aerosols. We report aerosol variations over India using multiple remote sensing datasets [Moderate Resolution Imaging Spectroradiometer (MODIS), Ozone Monitoring Instrument (OMI), Cloud-Aerosol Lidar, and Infrared Pathfinder (CALIPSO)], and model reanalysis [Copernicus Atmosphere Monitoring Service (CAMS)] during the lockdown implemented during the COVID-19 pandemic outbreak period from March 25 to April 14, 2020. Our analysis shows that, during this period, MODIS and CALIPSO showed a 30-40\% reduction in aerosol optical depth (AOD) over the Indo-Gangetic Plain (IGP) with respect to decadal climatology (2010-2019). The absorbing aerosol index and dust optical depth measurements also showed a notable reduction over the Indian region, highlighting less emission of anthropogenic dust and also a reduced dust transport from West Asia during the lockdown period. On the contrary, central India showed an 12\% AOD enhancement. CALIPSO measurements revealed that this increase was due to transported biomass burning aerosols. Analysis of MODIS fire data product and CAMS fire fluxes (black carbon, $\mathrm{SO}_{2}$, organic carbon, and nitrates) showed intense fire activity all over India but densely clustered over central India. Thus, we show that the lockdown restrictions implemented at the government level have significantly improved the air quality over northern India but fires offset its effects over central India. The biomass-burning aerosols formed a layer near 2-4 km (AOD 0.08-0.1) that produced heating at 3-4 K/day and a consequent negative radiative forcing at the surface of $\sim-65 \mathrm{~W} / \mathrm{m}^{2}\left( \pm 40 \mathrm{~W} / \mathrm{m}^{2}\right)$ over the central Indian region.

Keywords: COVID-19 lockdown, aerosol pollution over India, radiative forcing and heating, aerosol layer in the lower troposphere, fires over central India

\section{INTRODUCTION}

There are growing concerns about aerosol pollution over the Indian region due to the negative effects they produce on health and the hydrological cycle (Meehl et al., 2013; Vinoj et al., 2014; D'Errico et al., 2015; Fadnavis et al., 2017a; Fadnavis et al., 2019a). During the past decade, India recorded the highest levels of air pollution (World Bank and International report 2020). In India, 51\% of the 1.4 billion people population are persistently exposed to air pollution. Aerosol pollution over India has increased hazy days at a rate of 2.6 days per year (Thomas et al., 2019). This aerosol pollution has 
caused $8.8 \%$ of the total deaths (Report by Indian Council of Medical Research, 2017; IHME Report, 2019). Other than anthropogenic sources, smog events have proven fatal during the last decade (Spears et al., 2019; Pandey and Vinoj, 2021).

Aerosol pollution over the Indian region is attributed to economic development, traffic emissions, and land-use changes (Fadnavis et al., 2013; Guttikunda et al., 2014; Hama et al., 2020). Aerosol Radiative Forcing over India (ARFI) net observations show the rate of increase at $2.3 \%$ per year in aerosol loading over India (Krishna Moorthy et al., 2013). Pollution levels over urban and rural regions are equally high (Dey et al., 2012; Hammer et al., 2020). According to the Intergovernmental Panel on Climate Change (IPCC, 2014), India contributes $\sim 38-78 \%$ to the anthropogenic aerosol global mean and 3-9\% to biomassburning aerosol (David et al., 2019; IPCC, 2014). Agricultural fires and crop residue activity during winter/spring cause a substantial increase $(43 \%)$ in aerosol loading over North India (Jethva et al., 2019; Fadnavis et al., 2021).

The novel coronavirus (COVID-19) made its first appearance in December 2019 and quickly spread all over the world (Fadnavis et al., 2021). Transmission during the COVID-19 pandemic outbreak was facilitated by certain atmospheric conditions and pollutants (Lolli et al., 2020; Lolli and Vivone, 2020; Jiang et al., 2021). To restrict the spread of COVID-19, lockdown measures were imposed in January in China, and later in other countries all over the world (Chauhan and Singh, 2020; Paital, 2020; Yunus et al., 2020). India confirmed its first case on January 30, 2020, and later COVID-19 spread started rising exponentially. To strengthen the health infrastructure and restrict the spread of COVID-19, the Indian government imposed a Janata curfew on March 22, 2020 and, after that, a complete lockdown between March 25-April 14, 2020 (Chauhan and Singh, 2020).

The lockdown measures implemented at government level, e.g., restrictions on public transport, freights flights, shutting down industries, etc. reduced the aerosol optical depth (AOD) in different parts of the globe (Le Quéré et al., 2020; Kaskaoutis et al., 2021). The MODIS observations showed an $\sim 40 \%$ reduction in aerosols over North India (Gautam, 2020; Jain and Sharma, 2020; Fadnavis et al., 2021). The in-situ observations over Kanpur, a station in North India, showed a reduction of $20-30 \%$ of AOD compared to 2017-2019 (Shukla et al., 2020). A drop in AOD by 0.16 over the entire Indian landmass was reported by Mishra and Rathore (2021). There was a substantial decrease of $\sim 35 \%$ in the PM2.5 concentrations across the cities in the Indo-Gangetic belt (Das et al., 2021). However, there was an increase in AOD over south India (Le Quéré et al., 2020; Pandey and Vinoj 2021). The aerosol enhancement over South India is linked to local biomass burning activity (Singh et al., 2020; Sanap, 2021).

In this paper, we report how the aerosol vertical distribution impacted the heating rates and radiative forcing over India during the lockdown period of March 25-April 14, 2020. Our analysis shows a decrease in AOD over North India and enhancement over Central India $\left(78^{\circ} \mathrm{E}-85^{\circ} \mathrm{E}, 18^{\circ} \mathrm{N}-25^{\circ} \mathrm{N}\right)$. The aerosol enhancement over central India is due to large amounts of fires associated with agricultural activities. Further, we show that the smoke aerosols formed a layer of nearly $3-4 \mathrm{~km}$ that caused atmospheric heating and affected the radiative forcing over India. The results are derived from satellite observations (MODIS, OMI, CALIPSO) and CAMS reanalysis during March-April 2020. The paper is organized as follows: data and methodology are described in Section 2, results and discussions are given in Section 3, and conclusion are made in Section 4.

\section{DATA AND METHODOLOGY}

\subsection{Satellite Retrievals}

High-resolution vertical profiles of clouds and aerosols were obtained from the Cloud-Aerosol Lidar and Infrared Pathfinder Satellite (CALIPSO) (Winker et al.,2010; Winker et al., 2007). The CALIPSO payload, polarization-sensitive backscatter lidar, known as the Cloud-Aerosol Lidar with Orthogonal Polarization (CALIOP), operates at 532 and $1,064 \mathrm{~nm}$ wavelengths. The CALIPSO satellite has been observing the vertical distribution of aerosols since June 2006. The primary instrument on CALIPSO is CALIOP, a nadirviewing dual-wavelength (532 and $1,064 \mathrm{~nm}$ ) dual polarization at $532 \mathrm{~nm}$, elastic back-scatter lidar (Hunt et al., 2009). Level 2 algorithms detect features, assign type classification for aerosols, and retrieve extinction coefficients from the attenuated backscattered signals. The extinction algorithm retrieves vertical profiles of extinction, reported separately for aerosols and clouds. Aerosol extinction is not reported within clouds because the lidar signals are dominated by cloud scattering and so atmospheric features are classified as either aerosols or clouds and the retrieved extinction is reported for only one or the other. The aerosol profile product combines the profiles retrieved within aerosol layers to report vertical profiles of extinction coefficients at $5 \mathrm{~km}$ horizontal resolution. The vertical resolution is $60 \mathrm{~m}$ from 0.5 to $20.2 \mathrm{~km}$ and $180 \mathrm{~m}$ above $20.2 \mathrm{~km}$. For the $5 \mathrm{~km}$ along CALIPSO track horizontal averaging, 15 consecutive level $1 \mathrm{~B}$ profiles are used (Tackett et al., 2018). The lidar ratios and their uncertainties for several of the aerosol subtypes have been revised in version 4 (Kim et al., 2018). It is said that the reductions in the relative uncertainties associated with the improved lidar ratios will reduce the relative uncertainties in the retrieved extinction coefficients and optical depths. These improved lidar ratios in V4 are a better representative of actual conditions than in previous data releases (Young et al., 2018). Here, in the present study, we used the level 2 version 4.10/4.20 CALIPSO aerosol profile (APro) data for the period 2010-2020 (https://asdc.larc.nasa.gov/project/ CALIPSO). The details of the lidar ratio selection algorithm are well documented by Kim et al. (2018). We used the extinction profiles of aerosol and the optical depth for dust and elevated smoke aerosols at $532 \mathrm{~nm}$. These extinction profiles were used to calculate the aerosol optical depth profiles at pre-defined altitudes including higher numbers in the altitude-range $1-10 \mathrm{~km}$. We gridded these profiles at a $1 \times 1$ degree resolution.

The aerosol optical depth data obtained from the Moderate Resolution Imaging Spectroradiometer (MODIS) were also analyzed to understand aerosol variations over India. The 
MODIS sensor measures radiances at 36 bands, ranging from visible to infrared and varying spatial resolutions. Here, we used daily AOD at $550 \mathrm{~nm}$ from the MODIS (MOD08_D3) collection 6.1 level 3, combined dark target and deep blue, from 2010 to 2020 (Hsu et al., 2013; Levy et al., 2013; Wei et al., 2019a; Wei et al., 2019b) (https:/giovanni.gsfc.nasa.gov/giovanni). The past studies show that CALIPSO AOD is biased towards lower values as compared to MODIS (Kim et al., 2013). Kittaka et al. (2011) found that the biases between them vary with season and are higher over land than ocean. The observed biases may due to various reasons, e.g., MODIS has a higher frequency than CALIPSO (Ma et al., 2013).

We also analyzed Absorbing Aerosol Index (AAI) from the Ozone Monitoring Instrument (OMI) launched in 2004 (Torres et al., 2007). The level 3 data for the period 2010-2020 were obtained from http://giovanni.gsfc.nasa.gov/giovanni/. MODIS fire data (https://firms.modaps.eosdis.nasa.gov/active_fire/) were used to plot the location of fires during March-April 2020. The fire data with a confidence level above 80 were used to locate the fires.

\subsection{Reanalysis Data Sets}

We also used the Copernicus Atmosphere Monitoring Service (CAMS) near-real-time observations of the location and intensity of active fires to estimate the emissions of pollutants. The Copernicus Atmosphere Monitoring Services (CAMS) uses wildfire as a general term to describe active vegetation fires detectable by the satellite. This also includes forest, grassland and peat fires, and open burning of agricultural waste (https:// atmosphere.copernicus.eu/fire-monitoring). We referred to it as fires since during the lockdown period fires were mostly from agricultural burning. CAMS estimates are based on the Global Fire Assimilation System (GFAS). We also used the CAMSderived fluxes of black carbon, organic carbon, total carbon, sulphate, ammonia, and particulate matter that have a diameter of less than $2.5 \mu \mathrm{m}$ (PM2.5) for the period 2010-2020 (https://apps.ecmwf.int/datasets/data/cams-gfas/).

It should be noted that the horizontal resolution of all data sets used in this study (CALIPSO, MODIS, OMI, CAMS) is $1 \times 1$ degree and for the period 2010-2020. We show changes in AOD, dust optical depth, and elevated smoke optical depth during the lockdown period in comparison to climatology (2010-2019). To check whether these changes are significantly different than climatology, we apply two-sided Student's t-test (Zimmerman, 1987; Walpole and Raymond, 2006). If the $p$-value is less than 0.05 (95\% significance level), then we reject the null hypothesis and conclude that the differences are significant.

\subsection{Radiative Transfer Model}

The direct aerosol radiative forcing and heating rate are assessed through the one-dimensional parallel plane Fu-Liou-Gu (FLG) Radiative Transfer (RT) model (Fu and Liou, 1992; Fu and Liou, 1993; Gu et al., 2003; Gu et al., 2011; Lolli et al., 2019). The FLG RT code is initialized with the lidar vertically resolved CALIPSO optical depth profiles corresponding to the different aerosol species, which were matched to the Optical Properties of Aerosol and Clouds (OPAC) (D'Almeida et al., 1991; Tegen and Lacis, 1996; Hess et al., 1998). Catalog-based physical and optical models are embedded in the code (Gu et al., 2011). The number of levels of the RT model is adjusted to match CALIOP lidar resolution, i.e., the RT model and the vertically resolved lidar optical depth observation will have the same spatial resolution. The total aerosol radiative forcing is computed adding all contributions (in terms of optical depth) from the different aerosol species identified by the CALIPSO classification algorithm in the considered region and matched with the corresponding FLG aerosol species (Tosca et al., 2017).

From CALIOP data, among the 18 aerosol types parameterized within the FLG RT model from the OPAC catalog, we considered only the main two types of interest that match the CALIPSO classification: transported dust (CALIPSO: "dust") and black carbon (CALIPSO: "smoke"). To compute the radiative forcing at the top of the atmosphere and at the surface, the FLG RT model, which also accounts for aerosol hygroscopicity, solves the radiative fluxes at each level for 18 spectral bands (12 short-wave, 6 longwave, Fu and Liou, 1992; Fu and Liou, 1993). Nevertheless, an important source of error (potential) is represented by Version 4 CALIOP aerosol types parameterization into FLG RT. The CALIPSO classification algorithm is not able to distinguish between local urban pollution and an advected smoke aerosol layer from distant sources that descend below $2.5 \mathrm{~km}$. However, it is reasonable to suppose that those episodes are infrequent, but they can still occasionally introduce a bias in the analysis. For each annually averaged lidar extinction profile used as input in the FLG code, the aerosol direct radiative forcing (DRF) at the bottom of the atmosphere (surface) and top of the atmosphere (TOA) and the vertically resolved heating rate (HR) are computed. These estimates are obtained by subtracting the net radiative flux when the aerosols are present in the atmosphere from the net radiative flux obtained during pristine conditions, as shown in the following equation:

$$
\text { DRF, HR }=\text { FLG }^{\text {TotalSky }}-\text { FLG }^{\text {Pristine }}
$$

The other data that are needed as input to the FLG model (i.e., the temperature, the atmospheric thermodynamic variable profiles, the ozone concentration, and the mixing ratio) are obtained from the tropical standard atmosphere (USS976). The FLG radiative transfer model also needs the Solar Zenith Angle (SZA) for the computation. We use SZA for each box at noon local time of the 15th day of that month. Following the approach used in Landi et al. (2021), we applied a constant (wavelength-independent) albedo value of 0.12 for urban environments, 0.15 for vegetated areas, and 0.37 for desertic regions (obtained integrating the hemispherical directional reflectance, Strahler et al., 1999) while the infrared surface emissivity is set to a constant value of 0.98 .

\section{RESULTS AND DISCUSSIONS}

\subsection{Impact on Aerosol Optical Depth}

A significant reduction in AOD $(\sim 40 \%)$ over Western and Northern India during the lockdown period is evident from MODIS observations (Figure 1A). A similar reduction (a drop of $\sim 45 \%$ in AOD with respect to climatology 2010-2019) is also 


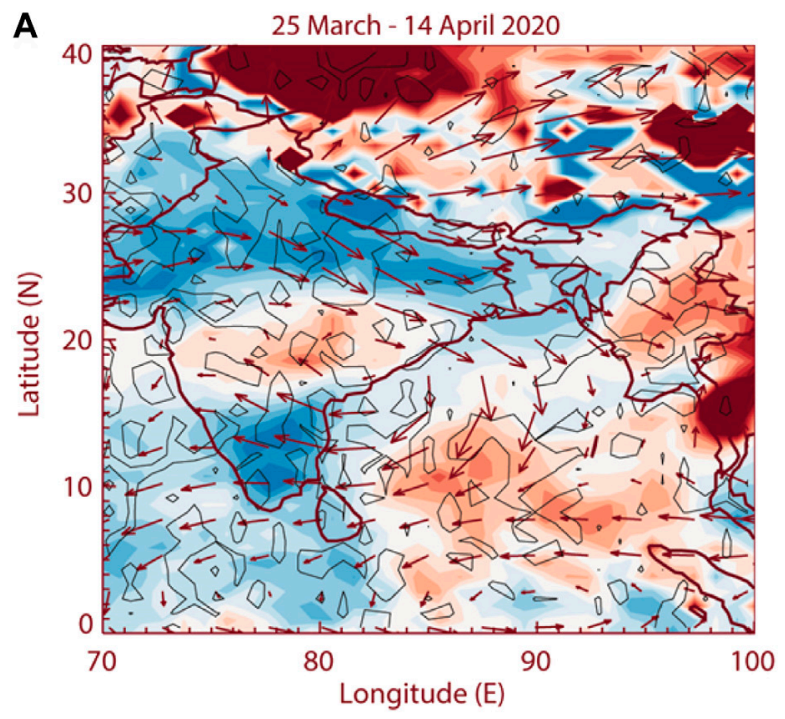

$-60.000-42.857-25.714-8.571 \quad 8.571 \quad 25.71442 .85760 .000$ Aerosol Optical Depth (\%)
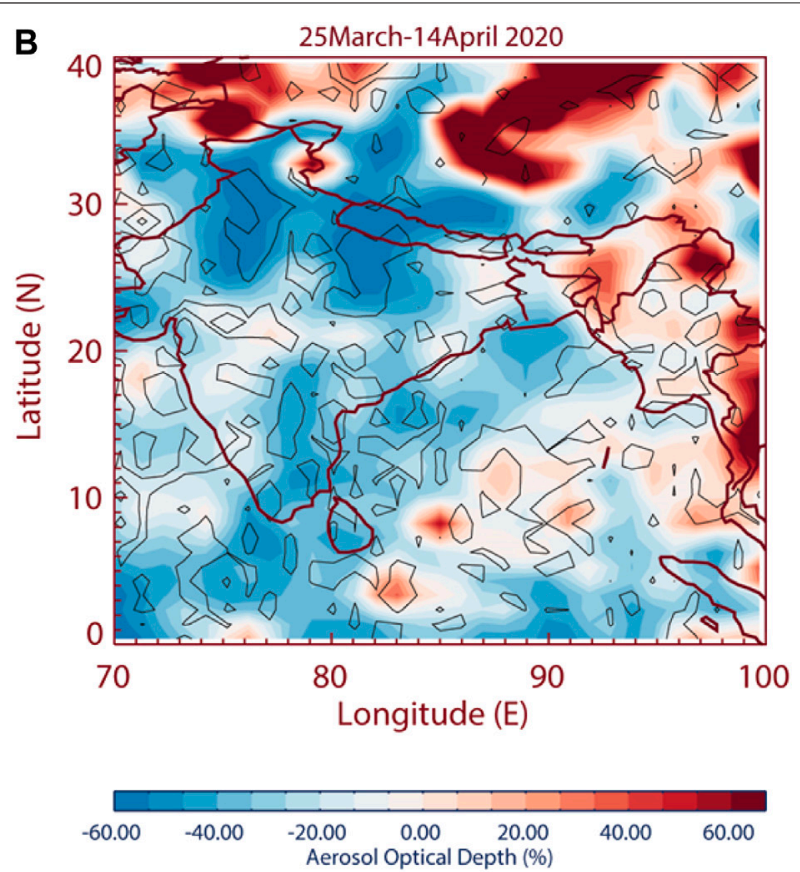

FIGURE 1 | (A) Spatial distribution of changes in AOD (2020-climatology) from MODIS at 550 nm (\%) and wind vectors at 850 hPa averaged for the lockdown period (March 25-April 14, 2020) are also shown in (A), (B) same as (A) but changes in AOD (2020-climatology) from CALIPSO at 532 nm. Contours in Panels (A,B) indicate $90 \%$ significance level.

showed by CALIPSO measurements over this region during the same period (Figure 1B). Recently, other studies also reported aerosol reduction over the parts of the Indian region during the lockdown period, e.g., Pathakoti et al. (2021) showed a decrease in AOD over the Indo-Gangetic plain by $\sim 24 \%$ (climatology 2015-2019) using MODIS data. While a study by Sanap (2021) showed a reduction of aerosols ( 16-27\%) over north India (climatology 2000-2020). Mishra and Rathore (2021) also reported an overall decrease in AOD by $60 \%$ (in comparison to 2019) over the Indian landmass.

MODIS AOD (Figure 1A) shows enhancement (5-30\%) over central India but it is faintly seen in CALIPSO (Figure 1B). It may be due to limited CALIPSO data (every 16 days overpass at the same location) during the lockdown period (Winker et al., 2007). The AOD enhancement over central India may be associated with aerosols emitted from fires (see discussions in Section 3.2). Interestingly, enhancement in AOD is also seen over the Bay of Bengal (12\%) and parts of the North Arabian Sea $\left(\sim 22^{\circ} \mathrm{N}\right)(5 \%)$ in MODIS data (Figure 1A). The atmospheric circulation (wind at $850 \mathrm{hPa}$ ) indicates that aerosol loading over the Bay of Bengal is associated with transport from India and Myanmar regions. During spring, anthropogenic and dust aerosols are transported from the Indo-Gangetic Plain and Myanmar region to the Bay of Bengal (Nair et al., 2016). In agreement with our results, past studies show evidence of anthropogenic (Satheesh et al., 2001; Kumar et al., 2014; Nair et al., 2016) and dust (Lakshmi et al., 2017) aerosol loading over the Bay of Bengal during the spring season. Trajectory analysis-based studies also show that anthropogenic aerosols over the Bay of Bengal are associated with transport from the Indian region (Nair et al., 2016). The aerosol enhancement over the Arabian Sea is due to transport from West Asia (Lau and Kim 2006). During spring, westerly winds transport dust from West Asia to the Arabian Sea (Vinoj et al., 2014; Fadnavis et al., 2017b). However, in spring 2020 dust transport from West Asia was suppressed (Fadnavis et al., 2021). A small enhancement (5\%) in AOD over the Arabian Sea may be due to the transport of small amounts of dust and biomass-burning aerosols from Saudi Arabia (Figure 1A) (Discussed in Section 3.2). The enhancement in AOD over the Bay of Bengal $\left(85^{\circ} \mathrm{E}-95^{\circ} \mathrm{E}, 0^{\circ} \mathrm{N}-10^{\circ} \mathrm{N}\right)$ is smaller in CALIPSO measurements than MODIS (Figure 1B) and no enhancement is seen over the Arabian Sea. It may be due to limited CALIPSO data as mentioned above.

\subsection{Distribution of Dust and Smoke Aerosols During Lockdown Period}

We understand the influence of dust transport from West Asia on the Indian region which occurs in spring (Lau and Kim 2006), here we show the changes in dust during the lockdown period using CALIPSO measurements of dust optical depth and the OMI aerosol index (OMI-AAI). The OMI-AAI over the deep inland area indicates dust aerosols (Brooks et al., 2019). The CALIPSO dust optical depth and OMI-AAI shows a reduction of $\sim 30 \%$ over the Indian region (Figures 2A,B). The Arabian Sea and Bay of Bengal regions show a widespread decrease $(\sim 20 \%)$ with pockets of a small enhancement in dust optical depth $(\sim 14 \%)$ and OMIAAI ( 20\%) (Figures 2A,B). It shows that during the lockdown 

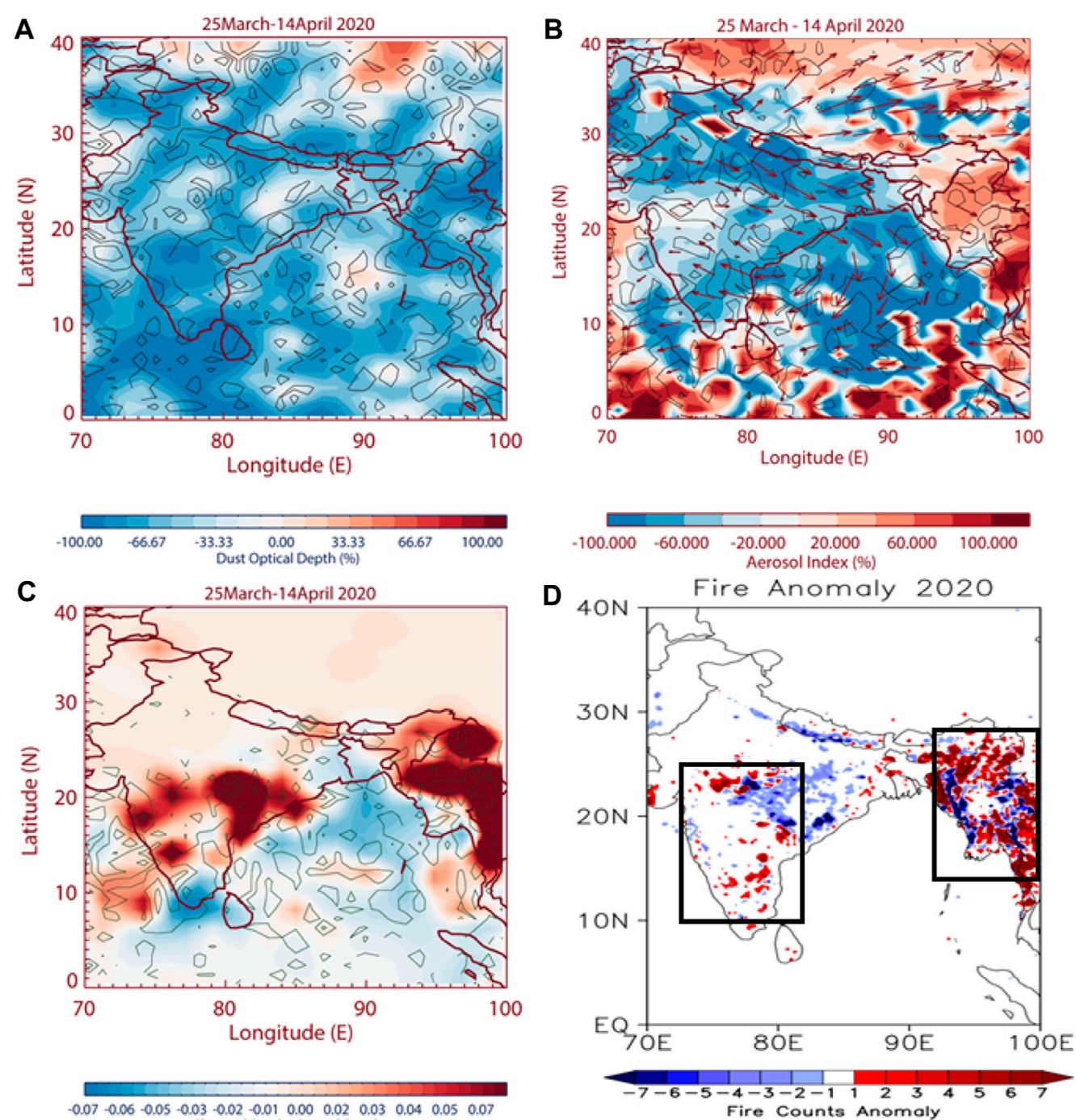

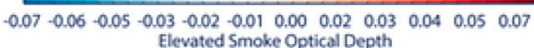

Fire Counts Anomaly

FIGURE 2 | (A) Spatial distribution of changes in dust optical depth (\%) from CALIPSO at $532 \mathrm{~nm}$, (B) spatial distribution of changes in OMl aerosol index (\%), (C) same as (A) but for CALIPSO elevated smoke optical depth at $532 \mathrm{~nm}$, (D) changes in fire counts distribution (2020-climatology) from MODIS. All the datasets are from the lockdown period March 25 to April 14. Contours in Panels (A-C) indicate a $95 \%$ significance level. Boxes $\left(10^{\circ} \mathrm{N}-25^{\circ} \mathrm{N} ; 72^{\circ} \mathrm{E}-81^{\circ} \mathrm{E}\right)$ in Panel (D) indicate the location of large numbers of fire anomalies.

period, in spring 2020, transport of dust from West Asia was lower than the climatology. The model simulations for COVID19 anthropogenic emission changes also showed a reduction of dust aerosols over the Arabian Sea in the spring of 2020. These simulations showed that the anthropogenic emission reductions had induced changes in atmospheric circulation that inhibited the transport of dust from West Asia to the Tibetan Plateau during spring 2020 (Fadnavis et al., 2021).

Further, we show anomalies in the vertical distribution of elevated smoke aerosols from the CALIPSO measurements during the lockdown period in Figure 2C. The elevated smoke is a name of a CALIPSO product for smoke layers with tops higher than the $2.5 \mathrm{~km}$ above the planetary boundary layer (McGrath-Spangler and Denning 2013; Kim et al., 2018). It shows positive anomalies over different parts of India that may be due to the presence of local fires as well as the longrange transport of biomass-burning aerosols. A striking feature seen in Figure 2C is a large enhancement (an increase of 0.08-0.1 with respect to climatology) in elevated smoke optical depth over 1) the central peninsular $\left(72^{\circ} \mathrm{E}-81^{\circ} \mathrm{E}, 10^{\circ} \mathrm{N}-25^{\circ} \mathrm{N}\right)$, 2) North-EastIndia-Myanmar region $\left(93^{\circ} \mathrm{E}-100^{\circ} \mathrm{E}, 15^{\circ} \mathrm{N}-25^{\circ} \mathrm{N}\right)$, and a part of IGP $\left(81^{\circ} \mathrm{E}-88^{\circ} \mathrm{E}, 26^{\circ} \mathrm{N}-31^{\circ} \mathrm{N}\right.$. Also, a high amount of smoke AOD is seen over eastern parts of central India $\left(15^{\circ} \mathrm{N}-24^{\circ} \mathrm{N} ; 77^{\circ} \mathrm{E}-82^{\circ} \mathrm{E}\right)$. Other parts of India also show a small enhancement in smoke optical depth that is substantially less than over the central peninsula, eastern-central India, and the North-East-IndiaMyanmar region (positive anomalies 0.02-0.03) above two regions. Smoke aerosols may be associated with the fire events hence we show anomalies of MODIS fire during the lockdown period (Figure 2D). Figure 2D shows negative anomalies over 

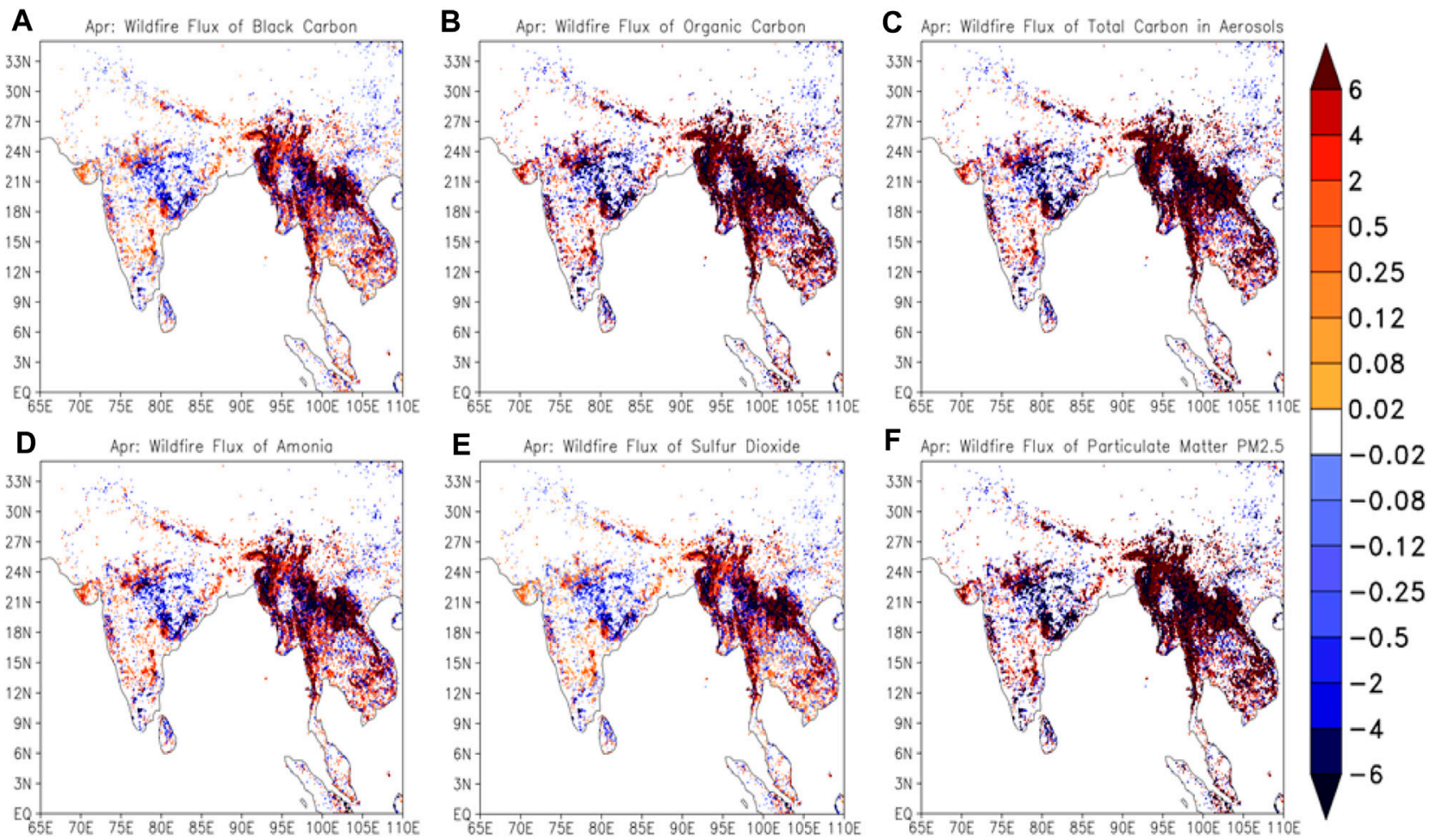

FIGURE 3 | (A-F): Fire flux $\left(\mathrm{kg} \mathrm{m}^{-2} \mathrm{~s}^{-1}\right)$ data for black carbon, organic carbon, total carbon, ammonia, sulfur dioxide, and particulate matter (PM2.5) for the lockdown period.

North India (blue color) and positive anomalies over southern India, the Northeast-India-Myanmar region, and over central India (indicated by boxes in Figure 2D). The regions of dense fire are collocated with higher amounts of smoke optical depth (Figure 2C). The contribution to elevated smoke aerosol optical depth over central India is due to these local fires as well as the transport of smoke aerosols emitted from the surrounding regions. High amounts of smoke anomalies over the eastern parts of central India are due to transport (see circulation in Figure 2B) and not directly emitted by the fires, since the fire anomalies are negative over eastern parts of central India. Higher amounts of smoke aerosols (positive anomalies 0.04-0.06) are seen over the Arabian Sea. The wind vectors indicate this enhancement is due to transport from central India (Figure 2C).

\subsection{Distribution of Fire Fluxes During Lockdown Period}

In this section, we show anomalies in the fire fluxes of black carbon, organic carbon, ammonia, sulfur dioxide, particulate matter (PM2.5), and total carbon aerosols during the lockdown period (Figures 3A-F). Regions of positive anomalies $(>1.5)$ are referred to as emission hotspots. The emission hotspots for organic carbon, black carbon, ammonia, sulphur dioxide fluxes (leads to the formation of sulfate aerosols), and particulate matter (PM 2.5) are collocated with the regions of dense fires during the lockdown (central peninsular and the North-East-India-Myanmar region). The positive anomalies of fire fluxes over southern India (Figure 3) are collocated with MODIS fire location (Figure 2D). This confirms that the increase in anomalous aerosol loading over 1) the central peninsular and 2) North-East-India-Myanmar region is due to fire emissions. Figures 1-3 show that, although the contribution of anthropogenic aerosols had reduced, the smoke aerosols over the central peninsular and North-East-India-Myanmar region caused an enhancement in AOD over these regions (Figures 1A,B, 2C,D).

\subsection{Heating Rate and Radiative Forcing}

Carbonaceous aerosols are key components of smoke that absorb solar radiation producing local atmospheric heating (Galanter et al., 2000; Zhang et al., 2020), while they produce a cooling effect on the climate via inhibiting solar radiation from reaching the surface (Shawki et al., 2018; Fadnavis et al., 2019b). During the lockdown period, enhanced smoke aerosols may have affected atmospheric heating. Here, we deliberate on heating rates and radiative forcing estimated from elevated smoke optical depth/ profiles averaged for the lockdown period.

Figure 4A shows the spatial distribution of elevated smoke optical depth from CALIPSO at $532 \mathrm{~nm}$ during the lockdown period. It shows a high amount of elevated smoke optical depth (Figure 2C), over 1) the central-peninsular region and 2) Northeast-India-Myanmar region, and low smoke optical 

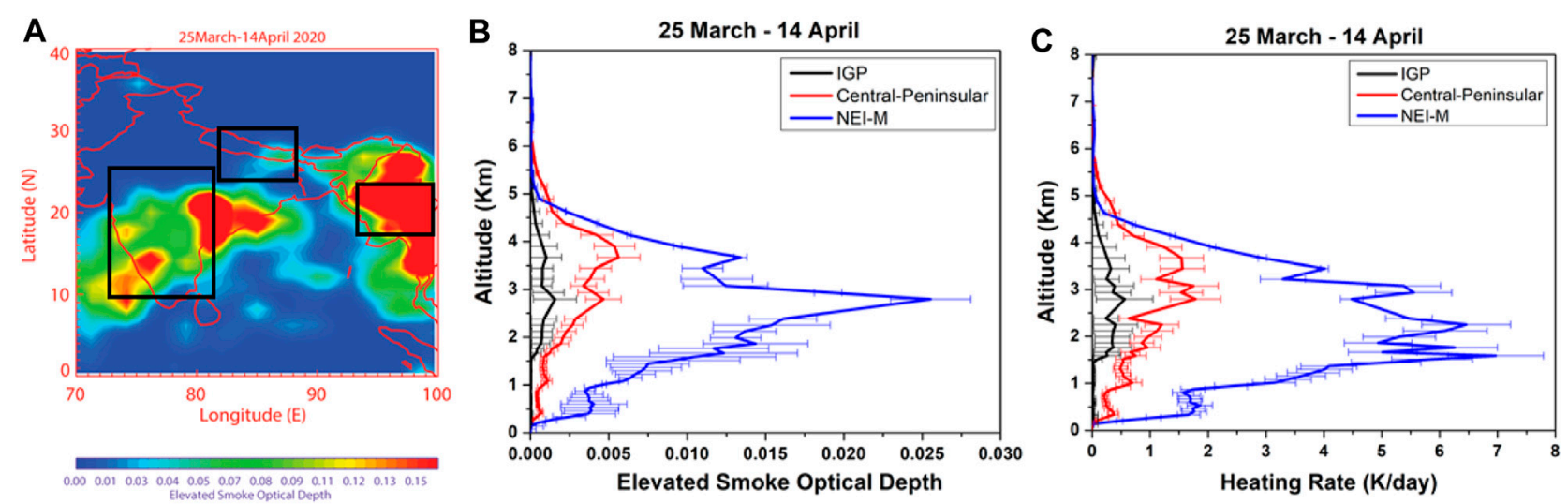

FIGURE 4 | (A) Spatial distribution of elevated smoke optical depth from CALIPSO, (B) profiles of elevated smoke optical depth averaged over the central peninsular, Northeast-India-Myanmar region, and IGP, (C) same as (B) but for heating rate (K/day). The horizontal lines in Panels (B,C) indicate standard deviation.

depth in 3) the IGP (depicted in Figure 4A by boxes). The high values of elevated smoke optical depth are also seen over eastern parts of central India due to transport (discussed in Section 3.2). Further we show vertical distribution of elevated smoke optical depth at the above three regions. There is a significant enhancement in elevated smoke aerosol optical depth $(0.002 \pm$ 0.001 to $0.0065 \pm 0.002)$ in the lower troposphere $(2-5 \mathrm{~km})$ over the central-peninsular region and $(0.008 \pm 0.001$ to $0.025 \pm 0.003)$ over the Northeast-India-Myanmar region. The enhancement over the IGP is significantly less than the abovementioned two regions due to comparatively fewer fires over the IGP. Interestingly, all three regions show an elevated layer of smoke aerosols between altitudes $2-5 \mathrm{~km}$. The elevated layers of smoke aerosols corroborate well with the regions of high aerosol optical depths observed over the central-peninsular and Northeast-India-Myanmar regions (Figure 3). Our analysis shows that the mean contribution due to elevated smoke aerosols to altitudes ranging from 2 to $5 \mathrm{~km}$ is $\sim 57 \%$ of the total columnar optical depth over the central peninsular and $\sim 68 \%$ over the Northeast-India-Myanmar region. While elevated smoke aerosols over the IGP contributed $\sim 18 \%$ to columnar optical depth the during lockdown period. Sarangi et al. (2016) reported the mean contribution of the aerosol layer from a $1.5-5.5 \mathrm{~km}$ altitude as $\sim 51-60 \%$ to the total columnar aerosol optical depth for the years 2009-2011 during May-June over Kanpur.

Figure 4C shows profiles of heating rate estimated from CALIPSO observations of elevated smoke aerosols over 1) the central peninsular, 2) Northeast-India-Myanmar region, and 3) IGP. Heating rate profiles over the Northeast-India-Myanmar region show a higher amount of heating than over the centralpeninsular region of India. It is quite evident that high amounts of elevated smoke aerosols during lockdown at altitudes between 2 and $5 \mathrm{~km}$ over the central peninsular have produced significant heating at $1.6 \mathrm{~K} /$ day $\pm 0.5 \mathrm{~K} /$ day at those altitudes and $\sim 6.5 \mathrm{~K} /$ day $\pm 0.5 \mathrm{~K} /$ day heating over the Northeast-India-Myanmar region. The IGP region shows comparatively less heating at $\sim 0.5 \mathrm{~K} /$ day $\pm 0.3 \mathrm{~K} /$ day at those altitudes due to smaller amounts of smoke aerosols. Strong warming is seen locally in the altitudes corresponding to higher amounts of elevated smoke optical depth. Also, a large increase in the heating rates is noticed below the peak in the smoke aerosol profile. For example, a peak in heating rates over the central peninsular is seen at $3 \mathrm{~km}$ while smoke aerosols show a peak at $3.8 \mathrm{~km}$. Similarly, over the Northeast-India-Myanmar region, heating rates are maximum at $2.2 \mathrm{~km}$ while the aerosol profile has a peak at $2.8 \mathrm{~km}$. This indicates that the peak in smoke aerosols and heating rates occurs at different altitudes. This may be due to aerosol heating occurring within a layer of atmosphere that retains and changes pressure values (Tripathi et al., 2007). Past studies showed enhancement in carbonaceous aerosols and increases in the heating rates by $0.08 \mathrm{~K} /$ day in the lower troposphere over India (Fadnavis et al., 2017a). The annual mean atmospheric heating rate due to the $\mathrm{BC}$ aerosols was $0.86 \mathrm{~K} /$ day over the Guwahati region during 2014 . Pani et al. (2018) estimated atmospheric heating of 1.4-3.6 K/day due to biomass-burning aerosols in the dry season over a station in southeast Asia.

Aerosol radiative forcing is defined as the net radiative change by aerosols present in the Earth system. Aerosols significantly impact the regional climate and this phenomenon has been largely studied (IPCC, 2014; Vinoj et al., 2014; Fadnavis et al., 2019a). Decoupling the elevated smoke aerosol optical depth from the atmospheric column, we estimate the biomass burning radiative forcing at the surface and top of the atmosphere (TOA) over 1) the central peninsular, 2) Northeast-India-Myanmar region, and 3) Indo-Gangetic Plain averaged for the lockdown period (Figure 5). The estimated radiative forcing at the TOA shows warming of $\sim 4.8 \mathrm{~W} / \mathrm{m}^{2}$ over the central-peninsular region, $\sim 15 \mathrm{~W} / \mathrm{m}^{2}$ over the Northeast-India-Myanmar region, and $\sim 1 \mathrm{~W} / \mathrm{m}^{2}$ over the IGP. The lower-tropospheric warming caused by elevated smoke aerosols has an implication on atmospheric circulation and cloud cover (Fadnavis et al., 2017b; Fadnavis et al., 2019b).

The estimated surface radiative forcing due to smoke aerosols over the central-peninsular region is $\sim-38 \mathrm{~W} / \mathrm{m}^{2}\left( \pm 15 \mathrm{~W} / \mathrm{m}^{2}\right)$, $\sim-152 \mathrm{~W} / \mathrm{m}^{2} \quad\left( \pm 50 \mathrm{~W} / \mathrm{m}^{2}\right)$ over the North-India-Myanmar 


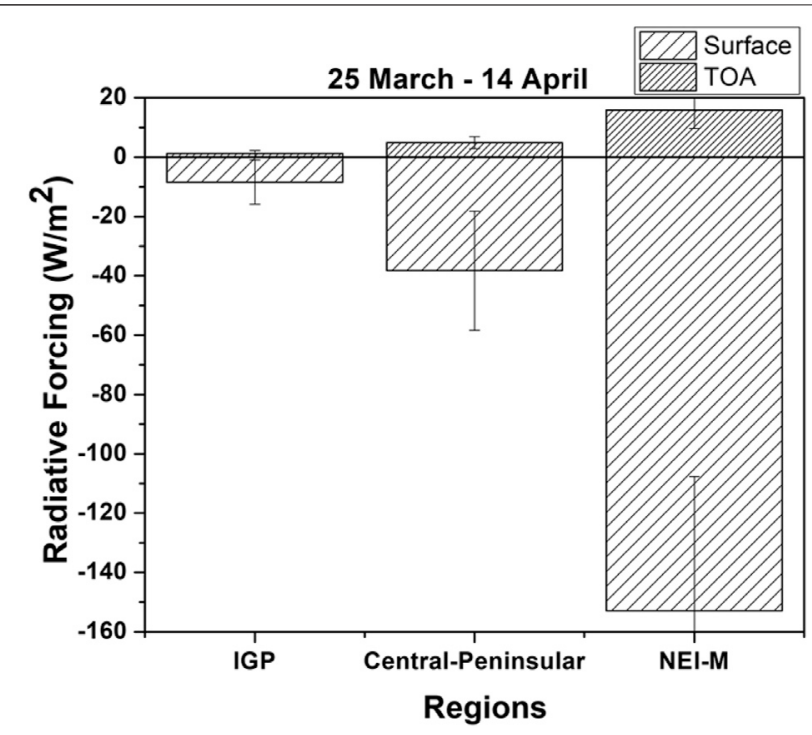

FIGURE 5 | Radiative forcing at the top of the atmosphere (TOA) and at the surface over central India, the Northeast-India-Myanmar region (NEI-M), and IGP. Vertical bars indicate standard deviation.

region, and $\sim-8 \mathrm{~W} / \mathrm{m}^{2}\left( \pm 9 \mathrm{~W} / \mathrm{m}^{2}\right)$ over the IGP. The amount of radiative forcing at the TOA (positive) and surface (negative) over the three regions is proportional to the amount of smoke aerosol, e.g., a large amount of smoke aerosols in the North-IndiaMyanmar region has imposed higher radiative impacts there than in the central peninsula and IGP (higher amount of surface cooling and warming at the TOA). All the three regions show warming in the atmosphere (in-atmospheric radiative forcing, TOA-surface), central India: $\sim 73 \mathrm{~W} / \mathrm{m}^{2}\left( \pm 40 \mathrm{~W} / \mathrm{m}^{2}\right)$, North-India-Myanmar region: $\sim 167 \mathrm{~W} / \mathrm{m}^{2}\left( \pm 50 \mathrm{~W} / \mathrm{m}^{2}\right)$, and IGP: $\sim 9 \mathrm{~W} / \mathrm{m}^{2}\left( \pm 9 \mathrm{~W} / \mathrm{m}^{2}\right)$.

A previous study also showed positive radiative forcing due to black carbon aerosols at the top of the atmosphere $\left(\sim 5 \mathrm{~W} / \mathrm{m}^{2}\right.$ over Bangalore, $\sim 9.5 \mathrm{~W} / \mathrm{m}^{2}$ over Guwahati), negative radiative forcing at the surface $\left(\sim-23 \mathrm{~W} / \mathrm{m}^{2}\right.$ over Bangalore and $\sim-21.1 \mathrm{~W} / \mathrm{m}^{2}$ over Guwahati), and in-atmospheric warming $\left(\sim 27 \mathrm{~W} / \mathrm{m}^{2} \pm 9 \mathrm{~W} /\right.$ $\mathrm{m}^{2}$ over the Indian region) (Babu et al., 2002; Tiwari et al., 2016; Nair et al., 2017).

Importantly, these studies show that smoke/carbonaceous aerosols produce positive radiative forcing at the top of the atmosphere, negative radiative forcing at the surface, and inatmospheric warming is agreement with our results. The atmospheric heating generated by smoke aerosols has implications on atmospheric circulation and cloud cover while the surface cooling might have effects on the precipitation changes (Lohmann and Feichter, 2005; Ward et al., 2012).

\section{CONCLUSION}

Diagnostic analysis of multiple data sets from Moderate Resolution Imaging Spectroradiometer (MODIS), Ozone Monitoring Instrument (OMI), Cloud-Aerosol Lidar, and
Infrared Pathfinder (CALIPSO), and Copernicus Atmosphere Monitoring Service (CAMS) during the lockdown period, March 25-April 14, 2020, showed that aerosols, in general, had reduced over north India, but there was an aerosol enhancement over central India and the Northeast-IndiaMyanmar region. This aerosol enhancement was due to fires. The fire-emitted smoke aerosols formed a layer at altitudes ranging from 2 to $5 \mathrm{~km}$ with subsequent enhancement in the aerosol optical depth of 0.002-0.005 over the central peninsular and $0.008-0.025$ over the Northeast-India-Myanmar region. The fires and smoke aerosols, both, were comparatively less over the IGP.

Elevated smoke aerosols have produced heating locally in the altitudes corresponding to the higher amount of elevated smoke optical depth. Also, a large increase in the heating rates is noticed below the peak in the smoke aerosol profile. For example, a peak in heating rates over central India is seen at $3 \mathrm{~km}$ while smoke aerosols show a peak at $3.5 \mathrm{~km}$. Similarly, over the Northeast-India-Myanmar region, heating rates were maximum at $2.2 \mathrm{~km}$ while aerosol profiles peaked at $2.8 \mathrm{~km}$. In general, heating of $\sim 1.6 \mathrm{~K} /$ day is seen over the central peninsula, $\sim 6 \mathrm{~K} /$ day over the Northeast-India-Myanmar region, and $\sim 0.3 \mathrm{~K} /$ day over the IGP. The smoke aerosols produced significant radiative impacts, warming effects at the top of the atmosphere, radiative forcing of $\sim 4.8 \mathrm{~W} / \mathrm{m}^{2}$ in the central peninsula and $\sim 15 \mathrm{~W} / \mathrm{m}^{2}$ in the Northeast-India-Myanmar region. The radiative forcing over the IGP was comparatively less $\left(1 \mathrm{~W} / \mathrm{m}^{2}\right)$ than the other two regions. A layer of smoke aerosol had produced a cooling effect at the surface over the Indian region (surface radiative forcing of $\sim-38 \mathrm{~W} / \mathrm{m}^{2}$ over the central peninsula, $\sim-152 \mathrm{~W} / \mathrm{m}^{2}$ over the Northeast-IndiaMyanmar region, and $-8 \mathrm{~W} / \mathrm{m}^{2}$ over the IGP) and warming in the atmosphere (central peninsula: $\sim 42.8 \mathrm{~W} / \mathrm{m}^{2}\left( \pm 15 \mathrm{~W} / \mathrm{m}^{2}\right)$, North-India-Myanmar region: $\sim 167 \mathrm{~W} / \mathrm{m}^{2}\left( \pm 50 \mathrm{~W} / \mathrm{m}^{2}\right)$, and IGP: $\sim 9 \mathrm{~W} / \mathrm{m}^{2}\left( \pm 9 \mathrm{~W} / \mathrm{m}^{2}\right)$. Thus, our study shows that significant atmospheric warming was produced by the smoke produced from fires, although anthropogenic aerosols were reduced during the lockdown period. Atmospheric warming has implications on circulation and precipitation (Fadnavis et al., 2021) and heats the lower atmosphere which causes incloud heating and changes in cloud albedos.

\section{DATA AVAILABILITY STATEMENT}

The original contributions presented in the study are included in the article/Supplementary Material, further inquiries can be directed to the corresponding author.

\section{AUTHOR CONTRIBUTIONS}

This article is the combined effort of all the authors. RB and SF formulated and wrote the article, with contributions from all coauthors. VK, PR, TS, and SL contributed to the analysis. SL carried computation of heating rates and radiative forcing using a radiative transfer model. 


\section{ACKNOWLEDGMENTS}

The authors thank all the reviewers for useful comments which helped improve the paper drastically. The author RB acknowledges with gratitude the Department of Science and Technology (DST), GoI, and Indo-US Science and Technology Forum (IUSSTF) for

\section{REFERENCES}

Babu, S. S., Satheesh, S. K., and Moorthy, K. K. (2002). Aerosol Radiative Forcing Due to Enhanced Black Carbon at an Urban Site in India. Geophys. Res. Lett. 29), 1880. doi:10.1029/2002GL015826

Brooks, J., Allan, J. D., Williams, P. I., Liu, D., Fox, C., Haywood, J., et al. (2019). Vertical and Horizontal Distribution of Submicron Aerosol Chemical Composition and Physical Characteristics across Northern India during Premonsoon and Monsoon Seasons. Atmos. Chem. Phys. 19, 5615-5634. doi:10.5194/acp-19-5615-2019

Chauhan, A., and Singh, R. P. (2020). Decline in PM2.5 Concentrations Over Major Cities Around the World Associated with COVID-19. Environ. Res. 187, 109634. doi:10.1016/j.envres.2020.109634

D’Errico, M., Cagnazzo, C., Fogli, P. G., Lau, W. K. M., Hardenberg, J., Fierli, F., et al. (2015). Indian Monsoon and the Elevated-heat-pump Mechanism in a Coupled Aerosol-Climate Model. J. Geophys. Res. Atmos. 120, 8712-8723. doi:10.1002/2015JD023346

D’Almeida, G. A., Koepke, P., and Shettle, E. P. (1991). Atmospheric Aerosol: Global Climatology and Radiative Characteristics. Hampton, Va: A. Deepak.

Das, M., Das, A., Sarkar, R., Saha, S., and Mandal, A. (2021). Examining the Impact of Lockdown (Due to COVID-19) on Ambient Aerosols (PM2.5): A Study on Indo-Gangetic Plain (IGP) Cities, India. Stoch Environ. Res. Risk Assess. 35, 1301-1317. doi:10.1007/s00477-020-01905-x

David, L. M., Ravishankara, A. R., Kodros, J. K., Pierce, J. R., Venkataraman, C., and Sadavarte, P. (2019). Premature Mortality Due to PM2.5Over India: Effect of Atmospheric Transport and Anthropogenic Emissions. GeoHealth 3, 2-10. doi:10.1029/2018gh000169

Dey, S., Di Girolamo, L., van Donkelaar, A., Tripathi, S. N., Gupta, T., and Mohan, M. (2012). Variability of Outdoor fine Particulate (PM2.5) Concentration in the Indian Subcontinent: A Remote Sensing Approach. Remote sensing Environ. 127, 153-161. doi:10.1016/j.rse.2012.08.021

Fadnavis, S., Sabin, T. P., Rap, A., Müller, R., Kubin, A., and Heinold, B. (2021). The Impact of COVID-19 Lockdown Measures on the Indian Summer Monsoon. Environ. Res. Lett. 16, 074054. doi:10.1088/1748-9326/ac109c

Fadnavis, S., Kalita, G., Kumar, K. R., Gasparini, B., and Li, J.-L. F. (2017b). Potential Impact of Carbonaceous Aerosol on the Upper Troposphere and Lower Stratosphere (UTLS) and Precipitation during Asian Summer Monsoon in a Global Model Simulation. Atmos. Chem. Phys. 17, 11637-11654. doi:10.5194/acp-17-11637-2017

Fadnavis, S., Müller, R., Kalita, G., Rowlinson, M., Rap, A., Li, J.-L. F., et al. (2019a). The Impact of Recent Changes in Asian Anthropogenic Emissions of $\mathrm{SO}_{2}$ on Sulfate Loading in the Upper Troposphere and Lower Stratosphere and the Associated Radiative Changes. Atmos. Chem. Phys. 19, 9989-10008. doi:10.5194/acp-19-9989-2019

Fadnavis, S., Roy, C., Sabin, T. P., Ayantika, D. C., and Ashok, K. (2017a). Potential Modulations of Pre-Monsoon Aerosols during El Niño: Impact on Indian Summer Monsoon. Clim. Dyn. 49, 2279-2290. doi:10.1007/s00382-016-3451-6

Fadnavis, S., Sabin, T. P., Roy, C., Rowlinson, M., Rap, A., Vernier, J.-P., et al. (2019b). Elevated Aerosol Layer over South Asia Worsens the Indian Droughts. Sci. Rep. 9, 10268. doi:10.1038/s41598-019-46704-9

Fadnavis, S., Semeniuk, K., Pozzoli, L., Schultz, M. G., Ghude, S. D., Das, S., et al. (2013). Transport of Aerosols into the UTLS and Their Impact on the Asian Monsoon Region as Seen in a Global Model Simulation. Atmos. Chem. Phys. 13, 8771-8786. doi:10.5194/acp-13-8771-2013

Fu, Q., and Liou, K. N. (1992). On the Correlatedk-Distribution Method for Radiative Transfer in Nonhomogeneous Atmospheres. J. Atmos. Sci. 49, 2139-2156. doi:10.1175/1520-0469(1992)049<2139:otcdmf $>2.0 . c 0 ; 2$ providing a WISTEMM Fellowship when the work was initiated. She also acknowledges the Ministry of Earth Sciences (MoES) as the data used and analyzed to prepare the paper were funded from this project. The UGC-FRP. CALIPSO, MODIS, OMI, and CAMS database teams and NASA websites from where data were downloaded are also acknowledged.

Fu, Q., and Liou, K. N. (1993). Parameterization of the Radiative Properties of Cirrus Clouds. J. Atmos. Sci. 50, 2008-2025. doi:10.1175/1520-0469(1993) $050<2008$ :potrpo $>2.0 . c 0 ; 2$

Galanter, M., Levy, H., and Carmichael, G. R. (2000). Impacts of Biomass Burning on Tropospheric CO, NOx, and O3. J. Geophys. Res. 105, 6633-6653. doi:10.1029/1999jd901113

Gautam, S. (2020). COVID-19: Air Pollution Remains Low as People Stay at home. Air Qual. Atmos. Health 13, 853-857. doi:10.1007/s11869-020-00842-6

Gu, Y., Farrara, J., Liou, K. N., and Mechoso, C. R. (2003). Parameterization of Cloud-Radiation Processes in the UCLA General Circulation Model. J. Clim. 16, 3357-3370. doi:10.1175/1520-0442(2003)016<3357:pocpit>2.0.co;2

Gu, Y., Liou, K. N., Ou, S. C., and Fovell, R. (2011). Cirrus Cloud Simulations Using WRF with Improved Radiation Parameterization and Increased Vertical Resolution. J. Geophys. Res. 116, D06119. doi:10.1029/2010JD014574

Guttikunda, S. K., Goel, R., and Pant, P. (2014). Nature of Air Pollution, Emission Sources, and Management in the Indian Cities. Atmos. Environ. 95, 501-510. doi:10.1016/j.atmosenv.2014.07.006

Hama, S. M. L., Kumar, P., Harrison, R. M., Bloss, W. J., Khare, M., Mishra, S., et al. (2020). Four-year Assessment of Ambient Particulate Matter and Trace Gases in theDelhi-NCR Region of India. Sustain. Cities Soc. 54, 102003. doi:10.1016/ j.scs.2019.102003

Hammer, M. S., van Donkelaar, A., Li, C., Lyapustin, A., Sayer, A. M., Hsu, N. C., et al. (2020). Global Estimates and Long-Term Trends of Fine Particulate Matter Concentrations (1998-2018). Environ. Sci. Technol. 54 (13), 7879-7890. doi:10.1021/acs.est.0c01764

Hess, M., Koepke, P., and Schult, I. (1998). Optical Properties of Aerosols and Clouds: The Software Package OPAC. Bull. Amer. Meteorol. Soc. 79, 831-844. doi:10.1175/1520-0477(1998)079<0831:opoaac >2.0.co;2

Hsu, N. C., Jeong, M.-J., Bettenhausen, C., Sayer, A. M., Hansell, R., Seftor, C. S., et al. (2013). Enhanced Deep Blue Aerosol Retrieval Algorithm: the Second Generation. J. Geophys. Res. Atmos. 118 (16), 9296-9315. doi:10.1002/jgrd.50712

Hunt, W. H., Winker, D. M., Vaughan, M. A., Powell, K. A., Lucker, P. L., and Weimer, C. (2009). CALIPSO Lidar Description and Performance Assessment. J. Atmos. Oceanic Technol. 26, 1214-1228. doi:10.1175/2009JTECHA1223.1

IHME Report (2019). Health and Economic Impact of Air Pollution in the States of India: The Global Burden of Disease Study 2019. Lancet Planet. Health 5, e25-38. doi:10.1016/S2542-5196(20)30298-9

IPCC (2014). Climate Change 2014: Synthesis Report. Contribution of Working Groups I, II and III to the Fifth Assessment Report of the Intergovernmental Panel on Climate Change. Lancet Planet. Health. Editors R. K. Pachauri and L. A. Meyer (Geneva, Switzerland: IPCC), 151.

Jain, S., and Sharma, T. (2020). Social and Travel Lockdown Impact Considering Coronavirus Disease (COVID-19) on Air Quality in Megacities of India: Present Benefits, Future Challenges and Way Forward. Aerosol Air Qual. Res. 20, 1222-1236. doi:10.4209/aaqr.2020.04.0171

Jethva, H., Torres, O., Field, R. D., Lyapustin, A., Gautam, R., and Kayetha, V. (2019). Connecting Crop Productivity, Residue Fires, and Air Quality over Northern India. Sci. Rep. 9 (1), 16594. doi:10.1038/s41598-019-52799-x

Jiang, Z., Shi, H., Zhao, B., Gu, Y., Zhu, Y., Miyazaki, K., et al. (2021). Modeling the Impact of COVID-19 on Air Quality in Southern California: Implications for Future Control Policies. Atmos. Chem. Phys. 21, 8693-8708. doi:10.5194/acp21-8693-2021

Kaskaoutis, D. G., Grivas, G., Liakakou, E., Kalivitis, N., Kouvarakis, G., Stavroulas, I., et al. (2021). Assessment of the COVID-19 Lockdown Effects on Spectral Aerosol Scattering and Absorption Properties in Athens, Greece. Atmosphere 12, 231. doi:10.3390/atmos12020231

Kim, M.-H., Kim, S.-W., Yoon, S.-C., and Omar, A. H. (2013). Comparison of Aerosol Optical Depth between CALIOP and MODIS-AQUA for CALIOP 
Aerosol Subtypes over the Ocean. J. Geophys. Res. Atmos. 118, 13241-13252. doi:10.1002/2013JD019527

Kim, M.-H., Omar, A. H., Tackett, J. L., Vaughan, M. A., Winker, D. M., Trepte, C. R., et al. (2018). The CALIPSO Version 4 Automated Aerosol Classification and Lidar Ratio Selection Algorithm. Atmos. Meas. Tech. 11, 6107-6135. doi:10.5194/amt-11-6107-2018

Kittaka, C., Winker, D. M., Vaughan, M. A., Omar, A., and Remer, L. A. (2011). Intercomparison of Column Aerosol Optical Depths from CALIPSO and MODIS-Aqua. Atmos. Meas. Tech. 4, 131-141. doi:10.5194/amt-4-131-2011

Krishna Moorthy, K., Suresh Babu, S., Manoj, M. R., and Satheesh, S. K. (2013). Buildup of Aerosols over the Indian Region. Geophys. Res. Lett. 40, 1011-1014. doi:10.1002/grl.50165

Kumar, R., Barth, M. C., Madronich, S., Naja, M., Carmichael, G. R., Pfister, G. G., et al. (2014). Effects of Dust Aerosols on Tropospheric Chemistry during a Typical Pre-monsoon Season Dust Storm in Northern India. Atmos. Chem. Phys. 14 (13), 6813-6834. doi:10.5194/acp-14-6813-2014

Lakshmi, N. B., Nair, V. S., and Suresh Babu, S. (2017). Vertical Structure of Aerosols and mineral Dust over the Bay of Bengal from Multisatellite Observations. J. Geophys. Res. Atmos. 122, 12,845-12,861. doi:10.1002/2017JD027643

Landi, T., Bonasoni, P., Brunetti, M., Campbell, J., Marquis, J., Di Girolamo, P., et al. (2021). Aerosol Direct Radiative Effects under Cloud-Free Conditions over Highly-Polluted Areas in Europe and Mediterranean: A Ten-Years Analysis (2007-2016). Remote Sensing 13 (15), 2933. doi:10.3390/rs13152933

Lau, K.-M., and Kim, K.-M. (2006). Observational Relationships between Aerosol and Asian Monsoon Rainfall, and Circulation. Geophys. Res. Lett. 33, L21810. doi:10.1029/2006GL027546

Le Quéré, C., Jackson, R. B., Jones, M. W., Smith, A. J. P., Abernethy, S., Andrew, R. M., et al. (2020). Temporary Reduction in Daily Global CO2 Emissions during the COVID-19 Forced Confinement. Nat. Clim. Chang. 10 (7), 647-653. doi:10.1038/s41558-020-0797-x

Levy, R. C., Mattoo, S., Munchak, L. A., Remer, L. A., Sayer, A. M., Patadia, F., et al. (2013). The Collection 6 MODIS Aerosol Products over Land and Ocean. Atmos. Meas. Tech. 6, 2989-3034. doi:10.5194/amt-6-2989-2013

Lohmann, U., and Feichter, J. (2005). Global Indirect Aerosol Effects: A Review. Atmos. Chem. Phys. 5, 715-737. doi:10.5194/acp-5-715-2005

Lolli, S., Chen, Y.-C., Wang, S.-H., and Vivone, G. (2020). Impact of Meteorological Conditions and Air Pollution on COVID-19 Pandemic Transmission in Italy. Sci. Rep. 10, 16213. doi:10.1038/s41598-020-73197-8

Lolli, S., Khor, W. Y., Matjafri, M. Z., and Lim, H. S. (2019). Monsoon Season Quantitative Assessment of Biomass Burning Clear-Sky Aerosol Radiative Effect at Surface by Ground-Based Lidar Observations in Pulau Pinang, Malaysia in 2014. Remote Sensing 11, 2660. doi:10.3390/rs11222660

Lolli, S., and Vivone, G. (2020). The Role of Tropospheric Ozone in Flagging COVID-19 Pandemic Transmission. Bull. Atmos. Sci. Technol. 1, 551-555. doi:10.1007/s42865-020-00026-1

Ma, X., Bartlett, K., Harmon, K., and Yu, F. (2013). Comparison of AOD between CALIPSO and MODIS: Significant Differences Over Major Dust and Biomass Burning Regions. Atmos. Meas. Tech. 6, 2391-2401. doi:10.5194/amt-6-23912013

McGrath-Spangler, E. L., and Denning, A. S. (2013). Global Seasonal Variations of Midday Planetary Boundary Layer Depth from CALIPSO Space-Borne LIDAR. J. Geophys. Res. Atmos. 118, 1226-1233. doi:10.1002/jgrd.50198

Meehl, G. A., Washington, W. M., Arblaster, J. M., Hu, A., Teng, H., Kay, J. E., et al. (2013). Climate Change Projections in CESM1(CAM5) Compared to CCSM4. J. Clim. 26, 6287-6308. doi:10.1175/JCLI-D-12-00572.1

Mishra, M. K., and Rathore, P. S. (2021). Impact of Nationwide COVID-19 Lockdown on Indian Air Quality in Terms of Aerosols as Observed from the Space. Aerosol Air Qual. Res. 21, 200461. doi:10.4209/aaqr.2020.07.0461

Nair, V. S., Babu, S. S., Gogoi, M. M., and Moorthy, K. K. (2016). Large-scale Enhancement in Aerosol Absorption in the Lower Free Troposphere over continental India during spring. Geophys. Res. Lett. 43, 11453-11461. doi:10.1002/2016GL070669

Nair, V. S., Babu, S. S., Manoj, M. R., Moorthy, K. K., and Chin, M. (2017). Direct Radiative Effects of Aerosols over South Asia from Observations and Modeling. Clim. Dyn. 49, 1411-1428. doi:10.1007/s00382-016-3384-0

Paital, B. (2020). Nurture to Nature via COVID-19, a Self-Regenerating Environmental Strategy of Environment in Global Context. Sci. Total Environ. 729, 139088. doi:10.1016/j.scitotenv.2020.139088
Pandey, S. K., and Vinoj, V. (2021). Surprising Changes in Aerosol Loading over India amid COVID-19 Lockdown. Aerosol Air Qual. Res. 21, 200466. doi:10.4209/aaqr.2020.07.0466

Pani, S. K., Lin, N.-H., Chantara, S., Wang, S.-H., Khamkaew, C., Prapamontol, T., et al. (2018). Radiative Response of Biomass-Burning Aerosols over an Urban Atmosphere in Northern Peninsular Southeast Asia. Sci. Total Environ. 633, 892-911. doi:10.1016/j.scitotenv.2018.03.204

Pathakoti, M., Muppalla, A., Hazra, S., Mahalakshmi, D. V., Sagar, K. K. V., Shekhar, R., et al. (2021). Measurement Report: An Assessment of the Impact of a Nationwide Lockdown on Air Pollution - a Remote Sensing Perspective over India. Atmos. chem. Phys. doi:10.5194/acp-21-90472021

Report by Indian Council of Medical Research (2017). ISBN: 978-81-910091-94.

Sanap, S. D. (2021). Global and Regional Variations in Aerosol Loading during COVID-19 Imposed Lockdown. Atmos. Environ. 246, 118132. doi:10.1016/ j.atmosenv.2020.118132

Sarangi, C., Tripathi, S. N., Mishra, A. K., Goel, A., and Welton, E. J. (2016). Elevated Aerosol Layers and Their Radiative Impact over Kanpur during Monsoon Onset Period. J. Geophys. Res. Atmos. 121, 7936-7957. doi:10.1002/2015JD024711

Satheesh, S. K., Moorthy, K. K., and Das, I. (2001). Aerosol Optical Depths Over Bay of Bengal, Indian Ocean and Arabian Sea. Curr. Sci. 81, 1617-1625.

Shawki, D., Voulgarakis, A., Chakraborty, A., Kasoar, M., and Srinivasan, J. (2018). The South Asian Monsoon Response to Remote Aerosols: Global and Regional Mechanisms. J. Geophys. Res. Atmos. 123, 11585-11601. doi:10.1029/2018JD028623

Shukla, N., Sharma, G. K., Baruah, P., Shukla, V. K., and Gargava, P. (2020). Impact of Shutdown Due to COVID-19 Pandemic on Aerosol Characteristics in Kanpur, India. J. Health Pollut. 10 (28), 201201. doi:10.5696/2156-961410.28.201201

Singh, T., Ravindra, K., Sreekanth, V., Gupta, P., Sembhi, H., Tripathi, S. N., et al. (2020). Climatological Trends in Satellite-Derived Aerosol Optical Depth over North India and its Relationship with Crop Residue Burning: RuralUrban Contrast. Sci. Total Environ. 748, 140963. doi:10.1016/ j.scitotenv.2020.140963

Spears, D., Dey, S., Chowdhury, S., Scovronick, N., Vyas, S., and Apte, J. (2019). The Association of Early-Life Exposure to Ambient PM2.5 and LaterChildhood Height-For-Age in India: an Observational Study. Environ. Health 18, 62. doi:10.1186/s12940-019-0501-7

Strahler, A. H., Muller, J., Lucht, W., Schaaf, C., Tsang, T., Gao, F., et al. (1999). MODIS BRDF/albedo Product: Algorithm Theoretical Basis Document Version 5.0. MODIS documentation 23 (4), 42-47.

Tackett, J. L., Winker, D. M., Getzewich, B. J., Vaughan, M. A., Young, S. A., and Kar, J. (2018). CALIPSO Lidar Level 3 Aerosol Profile Product: Version 3 Algorithm Design. Atmos. Meas. Tech. 11, 4129-4152. doi:10.5194/amt-114129-2018

Tegen, I., and Lacis, A. A. (1996). Modeling of Particle Size Distribution and its Influence on the Radiative Properties of mineral Dust Aerosol. J. Geophys. Res. 101, 19237-19244. doi:10.1029/95jd03610

Thomas, A., Sarangi, C., and Kanawade, V. P. (2019). Recent Increase in Winter Hazy Days over Central India and the Arabian Sea. Sci. Rep. 9, 17406. doi:10.1038/s41598-019-53630-3

Tiwari, S., Hopke, P. K., Attri, S. D., Soni, V. K., and Singh, A. K. (2016). Variability in Optical Properties of Atmospheric Aerosols and Their Frequency Distribution over a Mega City "New Delhi," India. Environ. Sci. Pollut. Res. 23 (9), 8781-8793. doi:10.1007/s11356-016-6060-3

Torres, O., Tanskanen, A., Veihelmann, B., Ahn, C., Braak, R., Bhartia, P. K., et al. (2007). Aerosols and Surface UV Products from Ozone Monitoring Instrument Observations: An Overview. J. Geophys. Res. 112, D24S47. doi:10.1029/ 2007JD008809

Tosca, M., Campbell, J., Garay, M., Lolli, S., Seidel, F., Marquis, J., et al. (2017). Attributing Accelerated Summertime Warming in the Southeast United States to Recent Reductions in Aerosol Burden: Indications from Vertically-Resolved Observations. Remote Sensing 9, 674. doi:10.3390/rs9070674

Tripathi, S. N., Srivastava, A. K., Dey, S., Satheesh, S. K., and Krishnamoorthy, K. (2007). The Vertical Profile of Atmospheric Heating Rate of Black Carbon Aerosols at Kanpur in Northern India. Atmos. Environ. 41, 6909-6915. doi:10.1016/j.atmosenv.2007.06.032 
Vinoj, V., Rasch, P. J., Yoon, H. J.-H., Landu, P.-L. K., and Singh, B. (2014). Shortterm Modulation of Indian Summer Monsoon Rainfall by West Asian Dust. Nat. Geosci. 7, 308-313. doi:10.1038/ngeo2107

Walpole, R. E., and Raymond, M. H. (2006). Probability \& Statistics for Engineers \& Scientists. 7th ed. New Delhi: Pearson. ISBN 81-7758-404-9. OCLC 818811849.

Ward, D. S., Kloster, S., Mahowald, N. M., Rogers, B. M., Randerson, J. T., and Hess, P. G. (2012). The Changing Radiative Forcing of Fires: Global Model Estimates for Past, Present and Future. Atmos. Chem. Phys. 12, 10857-10886. doi:10.5194/acp-12-10857-2012

Wei, J., Li, Z., Peng, Y., and Sun, L. (2019a). MODIS Collection 6.1 Aerosol Optical Depth Products over Land and Ocean: Validation and Comparison. Atmos. Environ. 201, 428-440. doi:10.1016/j.atmosenv.2018.12.004

Wei, J., Li, Z., Sun, L., Peng, Y., and Wang, L. (2019b). Improved Merge Schemes for MODIS Collection 6.1 Dark Target and Deep Blue Combined Aerosol Products. Atmos. Environ. 202, 315-327. doi:10.1016/j.atmosenv.2019.01.016

Winker, D. M., Hunt, W. H., and McGill, M. J. (2007). Initial Performance Assessment of CALIOP. Geophys. Res. Lett. 34, L19803. doi:10.1029/ 2007GL030135

Winker, D. M., Pelon, J., Coakley, J. A., Jr., Ackerman, S. A., Charlson, R. J., Colarco, P. R., et al. (2010). The CALIPSO Mission. Bull. Amer. Meteorol. Soc. 91, 1211-1230. doi:10.1175/2010BAMS3009.1

Young, S. A., Vaughan, M. A., Garnier, A., Tackett, J. L., Lambeth, J. D., and Powell, K. A. (2018). Extinction and Optical Depth Retrievals for CALIPSO's Version 4 Data Release. Atmos. Meas. Tech. 11, 5701-5727. doi:10.5194/amt-11-5701-2018

Yunus, A. P., Masago, Y., and Hijioka, Y. (2020). COVID-19 and Surface Water Quality: Improved lake Water Quality during the
Lockdown. Sci. Total Environ. 731, 139012. doi:10.1016/ j.scitotenv.2020.139012

Zhang, Y., Li, Z., Chen, Y., de Leeuw, G., Zhang, C., Xie, Y., et al. (2020). Improved Inversion of Aerosol Components in the Atmospheric Column from Remote Sensing Data. Atmos. Chem. Phys. 20, 12795-12811. doi:10.5194/acp-20-127952020

Zimmerman, D. W. (1987). Comparative Power of StudentTTest and MannWhitneyUTest for Unequal Sample Sizes and Variances. J. Exp. Educ. 55 (3), 171-174. doi:10.1080/00220973.1987.10806451

Conflict of Interest: The authors declare that the research was conducted in the absence of any commercial or financial relationships that could be construed as a potential conflict of interest.

Publisher's Note: All claims expressed in this article are solely those of the authors and do not necessarily represent those of their affiliated organizations, or those of the publisher, the editors and the reviewers. Any product that may be evaluated in this article, or claim that may be made by its manufacturer, is not guaranteed or endorsed by the publisher.

Copyright (c) 2021 Bhawar, Fadnavis, Kumar, Rahul, Sinha and Lolli. This is an open-access article distributed under the terms of the Creative Commons Attribution License (CC BY). The use, distribution or reproduction in other forums is permitted, provided the original author(s) and the copyright owner(s) are credited and that the original publication in this journal is cited, in accordance with accepted academic practice. No use, distribution or reproduction is permitted which does not comply with these terms. 